\title{
A Modified Gauss Plume Model for Drawing the Distribution of PM2.5
}

\author{
Jia Mengshuo \\ Department of Electrical engineering and its automation \\ North China Electric Power University \\ Baoding,China \\ e-mail: jiam5588@163.com
}

\begin{abstract}
At present, the broadcast of PM2.5 can't be accurate to all the spot of the city. This paper discusses a new method to draw the distribution of PM2.5 of a city by using mass data provided by the monitoring stations, which can be accurate to all the spot. In order to solve the problem efficiently, we present modified Gauss plume model. In the proposed model, firstly, for the accuracy of the model, we put forward a new method to calculate the wind direction. In addition, through the geometric inversion of the wind direction, the pollution source can be found. Moreover, in order to simulate the real situation, we replace the normal distribution by chi square distribution in Gauss plume model. Finally, the whole distribution of PM2.5 of the city can be draw. The PM2.5 distribution of Beijing in 2014 March indicates the proposed model is effective and feasible.
\end{abstract}

Keywords-PM2.5;data mining;pollution source; modified Gauss plume model; geometric inversion

\section{INTRODUCTION}

At present, the problem of PM2.5perplex developing countries, especially China. Beijing and Hebei province are the heavy disaster area of PM2.5. Lots of monitoring stations are constructed but a vast of data is wasted. Through data mining ${ }^{[1]}$, drawing the distribution of PM2.5 can clearly show the position of pollution source, and get the value of PM2.5 of all the spot of a city.

There are plenty of method to calculate the wind direction. $\mathrm{Wu}$ and Qian put forward a ladder average method to calculate the wind direction ${ }^{[2]}$. By comparing the PM2.5 change rate of every monitoring stations, using distance and thedifference of two stations to construct weight, We put forward a new method of calculating wind direction.

Finding the position of pollution source is the key to continue the work. Yang and Zhang numerical simulation to find the pollution source position by inversion ${ }^{[3]}$, but the numerical simulation assume that the atmospheric flow field is stable without velocity, which is not the real reflect of the atmospheric flow field. According to the rule that PM2.5 change rate is decline on the leeward wind, every two PM2.5 monitoring stations with different PM2.5 value can provide a leeward wind vector. Every two leeward wind vectors cross reversely, and the cross point might be the position of pollution source. Using mesh generation with $0.1 \times 0.2$ resolution to count the distribution of pollution source, and finally determine the real position of pollution source.
After determining the position of pollution source, use suitable model to simulate the diffusion of PM2.5 can solve the problem. $\mathrm{Hu}, \mathrm{Gao}$ and Jin use Kriging interpolation to realize optimal interpolation, and build partial differential function model to simulate the diffusion $^{[4]}$. But Kriging interpolation is more suitable for soil instead of air. Wu put up with a atmospheric point source Gauss plume model based on GIS ${ }^{[5]}$. Gauss plume model is suitable for air, however, the atmospheric point source Gauss plume model assume that the pollution concentration on the axis obeys normal distribution, which is ideal. We change it into chi square distribution considering the wind.

Through the modified Gauss plume model, the distribution of PM2.5 of all the spot of a city can be draw. And the position of pollution source is quite clear on the picture.

In order to test our model, we take the PM2.5 data of Beijing in 2014 March, which involving 35 monitoring stations and PM2.5 value every hour. We draw the distribution of PM2.5 of Beijing, and find the position of pollution source is all near the heavy industries.

The paper is organized as follows. In the next section, we propose the model that we research in this paper, and some definitions and assumptions are given. In Section 3, the new method of calculating wind direction is presented. Section 4 presents the geometric inversion to find pollution source. In Section 5, modified Gauss plume model is made to draw the distribution of PM2.5. Finally, we provide the result of Beijing's PM2.5 disribution and conclude our paper in section 6 .

\section{ASSUMPTIONS}

Diffusion process does not take the changes in temperature inside the cloud, ignoring heat transfer, thermal convection and heat radiation into account.

- Diffusion process obeys ideal gas equation.

- Air diffusion coefficients is isotropic in horizontal direction.

- Initial concentration and temperature within the cloud is uniform distribution 


\section{A NEW METHOD OF CALCULATING WIND DIRECTION}

Take 6 monitoring stations $e_{1}, e_{2}, e_{3}, e_{4}, e_{5}, e_{6}$ for example. Using method of digit by digit calculate the change rate of each station:

$$
\frac{\partial e_{i}}{\partial \mathrm{t}}=\frac{\Delta e_{i}}{\Delta t}
$$

Where $\frac{\partial e_{i}}{\partial t}$ is the change rate. Link the point $e_{l}$ and $e_{6}$. If $\frac{\partial e_{1}}{\partial \mathrm{t}}>\frac{\partial e_{6}}{\partial \mathrm{t}}$, then one component of the wind is from $e_{6}$ to $e_{1}$. Use $\vec{I}_{6 \rightarrow 1}$ directed line segment represent the wind component vector.

The whole wind component vectors forms the wind direction. The weight of each wind component vectors is defined by the change rate difference of two stations and the distance between them.

$$
w_{i \rightarrow k}=\frac{\left|\frac{\partial e_{i}}{\partial \mathrm{t}}-\frac{\partial e_{k}}{\partial \mathrm{t}}\right|}{\vec{I}_{i \rightarrow k}}
$$

Where $w_{i \rightarrow k}$ is the weight of the wind component from station $i$ to station $k$. The higher the difference change rate between the two stations is, the shorter the distance between them is, the bigger the weight is. The direction of the wind component is defined by latitude and longitude:

$$
\tan \alpha_{i \rightarrow k}=\frac{e_{j i}-e_{j k}}{e_{w i}-e_{w k}}(3)
$$

Where $e_{j i}$ is the longitude of station $i, e_{j k}$ is the longitude of station $k, e_{w_{i}}$ is the latitude of station $i$, $e_{w k}$ is the latitude of station $k$. Therefore, combine the weight and the direction of each wind component, we obtain the wind direction:

$$
\tan \alpha=\frac{\sum_{i=1}^{n} \sum_{k=i+1}^{n}\left(w_{i \rightarrow k} \times \tan \alpha_{i \rightarrow k}\right)}{\sum_{i=1}^{n} \sum_{k=i+1}^{n} w_{i \rightarrow k}}
$$

\section{FINDING POLLUTION SOURCE}

As motioned above, the wind component is defined by the change rate of PM2.5. The pollution source is at the upstream of the wind component. Thus two wind components cross reversely, the cross point is the possible pollution source.

Take 6 monitoring stations $e_{1}, e_{2}, e_{3}, e_{4}, e_{5}, e_{6}$ for example. On the condition of $\frac{\partial e_{1}}{\partial \mathrm{t}}>\frac{\partial e_{6}}{\partial \mathrm{t}}$ and $\frac{\partial e_{4}}{\partial \mathrm{t}}>\frac{\partial e_{5}}{\partial \mathrm{t}}$.

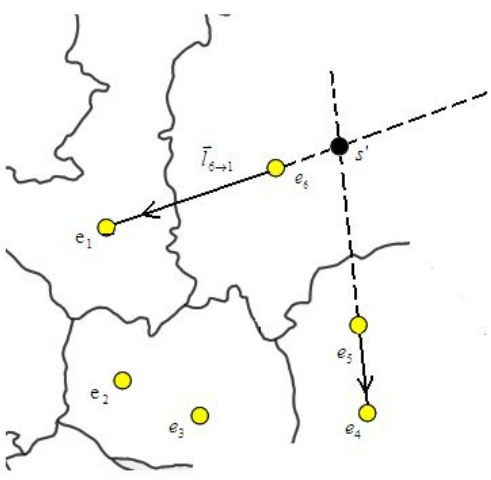

Figure 1.The Possible Pollution Source

The possible pollution source $s$ ' is showed in Fig.1. However, the possible pollution source should be screened to find the real pollution source. Thus we put up with the mesh generation ${ }^{[6]}$ with $0.1 \times 0.2$ resolution to count the distribution of pollution source, and finally determine the real position of pollution source.

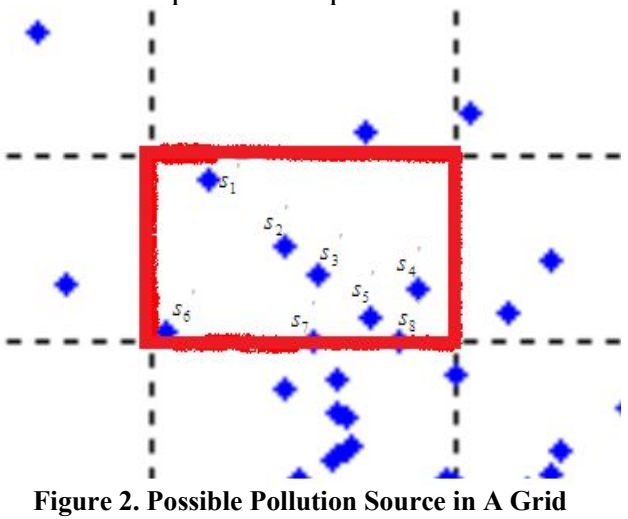

In Fig. 2, there are 8 possible pollution sources froms 1 to $s_{8}$. We assume that there is only one real pollution source in one grid. As for the source on the border line, we choose the top line and left line instead of the bottom line and the right line. Thus the position of real pollution source position can be defined as:

$$
\left\{\begin{array}{l}
s_{w}=\frac{\sum_{i=1}^{n} s_{w i}^{\prime}}{n} \\
s_{j}=\frac{\sum_{i=1}^{n} s_{j i}^{\prime}}{n}
\end{array}\right.
$$

Where $s_{w}$ is the latitude of the position of the real pollution source,and $s_{j}$ is the longitude of the position of the real pollution source.

\section{MODIFIED GAUSS PLUME MODEL}

\section{A. Coordinate transformation}

The position of the real pollution sources and the monitoring stations is defined by latitude and longitude. The coordinate should be transformed into Gauss coordinate $^{[7]}$. 


$$
\left\{\begin{array}{c}
\vec{p}=\left(x_{p}-x_{s}, y_{p}-y_{s}\right) \\
x_{g p}=\left|\vec{p} \times \vec{e}_{w}\right| \\
y_{g p}=\left|\vec{p} \times \vec{e}_{w}\right|
\end{array}\right.
$$

Where $\vec{p}, x_{g p}, y_{g p}, x_{p}, x_{s}, y_{p}, y_{s}, \vec{e}_{w}$ and $\vec{e}_{w}^{\prime}$ are showed in the next figure:

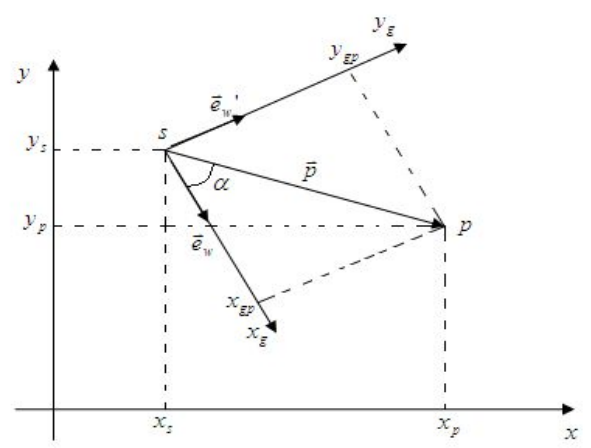

Figure 3. Coordinate transformation

\section{B. Gauss plume model}

At the centre of pollution source, the diffusion of PM2.5 is as the Fig. 4 show ${ }^{[8]}$.

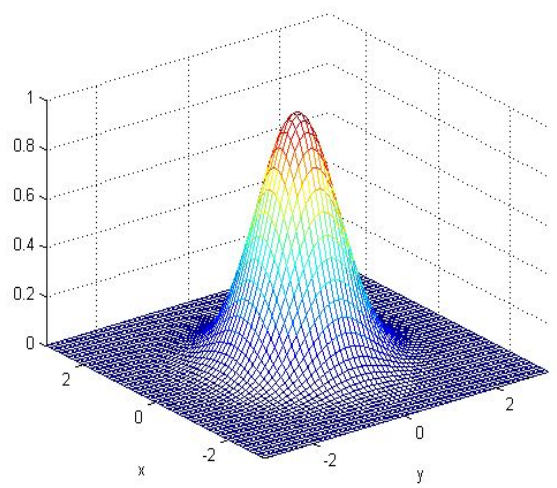

Figure 4. PM2.5 Diffusion

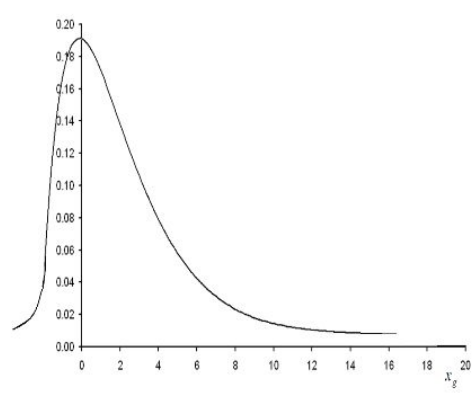

Figure 5. $x$ Axis Section

Extract the section which is parallel to $\mathrm{x}$ axis, we obtain the Fig.5. As can be seen from the figure, the diffusion obeys chi square distribution.

$$
f\left(x_{g}\right)=\left\{\begin{array}{l}
\frac{1}{2^{n / 2} \Gamma(n / 2)} x_{g}^{\frac{n}{2}-1} e^{\frac{-x_{g}}{2}}, x_{g}>0(7) \\
0, x_{g} \leq 0
\end{array}\right.
$$

As for $y$ and $z$ axis, the diffusion obeys normal distribution.

$$
f\left(y_{g}\right)=\frac{1}{\sqrt{2 \pi} \sigma} e^{\left(-\frac{\left(y_{g}-\mu\right)^{2}}{2 \sigma^{2}}\right)}
$$

Therefore, we put up with the modified Gauss plume model[ ${ }^{[9]}$.

$$
\begin{gathered}
f\left(x_{g}, y_{g}\right)=a\left(x_{g}-b\right)^{1} e^{-\left(\frac{x_{g}-1}{2 e}\right)} e^{-\frac{y_{g}{ }^{2}}{c}}+d \\
\text { (9) } \sum_{m=1}^{n} f\left(x_{g m}, y_{g m}\right)=\sum_{m=1}^{n} a\left(x_{g m}-b\right) e^{-\left(\frac{x_{g m}-1}{2 e}\right)} e^{-\frac{y_{g m}{ }^{2}}{c}}+d(1
\end{gathered}
$$

Where $f_{m}\left(x_{m}, y_{m}\right)$ is the contribution of the $m$ th pollution source to monitoring station. $\left(x_{m}, y_{m}\right)$ is the coordinate of the station. $a, b, c$ and $d$ are four parameters. After the fitting of historical data by using the PM2.5 value of the stations, the four parameters can be set.

\section{COMPUTATIONAL EXAMPLES AND ANALYSIS}

In order to illustrate the feasibility and effectiveness of the model, we use the PM2.5 data in 2014 March Beijing.

The data is the PM2.5 of 35 stations of every hour in 2014 March.

Step1: (Calculating wind direction)By using (4), we calculate 10 days from $1^{\text {st }}$ March to $10^{\text {th }}$ in Table 1 .

\begin{tabular}{c|c}
\hline \multicolumn{2}{c}{ TABLE 1. Wind Direction } \\
\hline \hline Date & \\
\hline $1^{\text {st }}$ March & 0.4022 \\
$2^{\text {nd }}$ March & 0.5799 \\
$3^{\text {rd }}$ March & 0.5881 \\
$4^{\text {th }}$ March & 1.8167 \\
$5^{\text {th }}$ March & 0.5602 \\
$6^{\text {th }}$ March & 1.4155 \\
$7^{\text {th }}$ March & 0.6362 \\
$8^{\text {th }}$ March & 2.2877 \\
$9^{\text {th }}$ March & 0.1938 \\
$10^{\text {th }}$ March & 2.2897 \\
\hline \hline
\end{tabular}

Step2: (Finding pollution source) By using (5), we calculate the pollution sources' position in $8^{\text {th }}$ March, and show the distribution ${ }^{[10]}$ in Fig.6. The pollution sources are around Shijingshan region, Fengtai region and Yizhuang region, which are three heavy industries region.

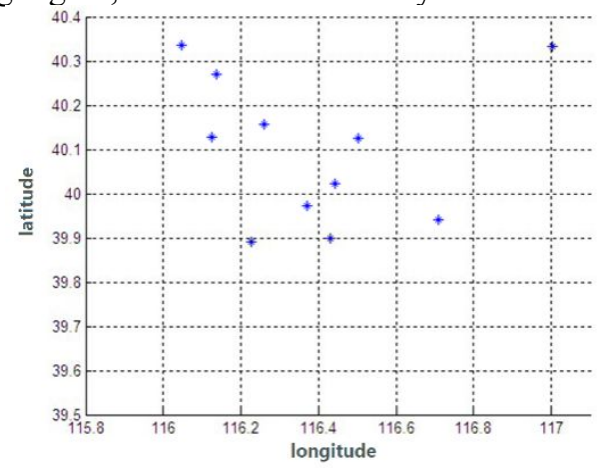

Figure 6. Pollution Sources Distribution

Step 3: (Building model) By using (10) and historical data, we obtain 5 days value of the four parameters of $a, b$, 
$c$ and $d$ in table 2. Use the value of $4^{\text {th }}$ March to draw the distribution of PM2.5 of Beijing and the result is showed in Fig.7.

TABLE 3. Four Parameters Value

\begin{tabular}{c|c|c|c|c}
\multicolumn{5}{|c}{ TABLE 3. Four Parameters Value } \\
\hline \hline Date & $\mathrm{a}$ & $\mathrm{b}$ & $\mathrm{c}$ & $\mathrm{d}$ \\
\hline $1^{\text {st }}$ March & 30.06 & -24.09 & 800.00 & 10.11 \\
$2^{\text {nd }}$ March & 95.77 & -53.81 & 800.00 & 125.13 \\
$3^{\text {rd }}$ March & 124.94 & -20.38 & 800.00 & 202.87 \\
$4^{\text {th }}$ March & 58.44 & -34.42 & 800.01 & 65.07 \\
$5^{\text {th }}$ March & 83.70 & -43.10 & 800.06 & 77.00 \\
\hline \hline
\end{tabular}

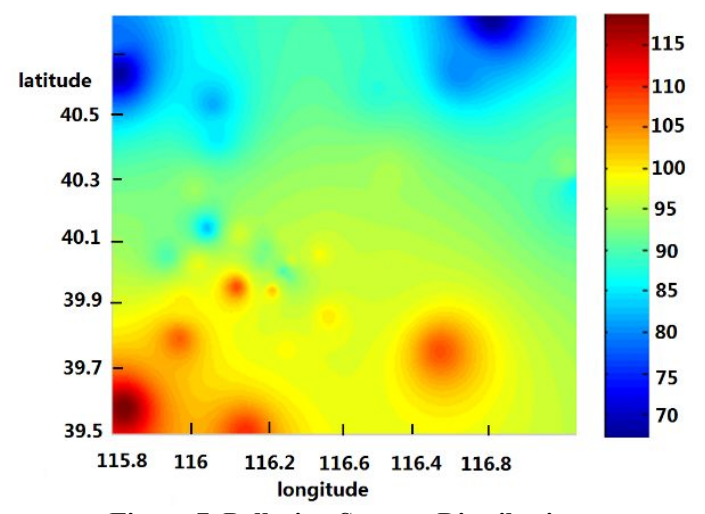

Figure 7. Pollution Sources Distribution

According to the distribution of PM2.5 in Fig.7, the heaviest region is the area around 39.7,116, where a cement plant is in motion. The lowest PM2.5 region is the area around $40.6,115.8$, where vast territory mountains is in this area. The result shows our model is effective and feasible.

\section{CONCLUSIONS}

In the proposed model, differed from traditional model, normal distribution is replaced by chi square distribution. And the new method of calculating wind direction improve the accuracy of the model. By using geometric inversionand mesh generation to find pollution source provide the condition for modified Gauss plume model.
To conclude, this model not only can draw the distribution of PM2.5 of a city by using the data provided by the monitoring stations, but also can calculate the wind direction and find the real pollution sources.

\section{ACKNOWLEDGMENT}

The research work was supported by Hebei province Undergraduates Innovating Experimentation Project No. 201410079207.

I shall extend my thanks to Mrs. Zhang for all her kindness and help. I wouldalso like to thank all my teachers who have helped me to develop the fundamentaland essential academic competence.

\section{REFERENCES}

[1] Chen. M.S, Han. J.W, and Yu. P.S, "Data mining: an overview from a database perspective."IEEE Transactions on Knowledge and Data Engineering,vol.6, pp. 866 - 883, Aug 2002.

[2] Wu. C.H, and Qian. Y.P, "Research and testing for average wind direction based on ladder mean algorithm."Journal of meteorological science and technology, vol.5, pp. 107-115, Oct 2011.

[3] Yang. Y.F, and Zhang. K.S, "Numerical simulation on source identification of accidentally occurring air pollution."Acta Scientiae Circumstantiae, vol.9, pp. 2388-2394, Sep 2013.

[4] Hu. J, Gao. M.J andJin. Y.S, "Research on simulation of Gaussian plume model of atmosphere dispersion based on GIS,"Journal of Nantong vocational college, vol.2, pp. 64-74, June 2012.

[5] Wu. Y.M, "Pollutants propagation model based on diffusion function."East China Normal University,May 2010.

[6] Lo. S.H, "A new mesh generation scheme for arbitrary planar domains."International Journal for Numerical Methods in Engineering, vol.8, pp. 1403-1426, Aug 1985.

[7] Li. S and Hu. S.W, "Research on the transformation from independent coordinate system to Gaussian coordinate system," Science of Surveying and Mapping, vol.S2, 2009.

[8] Sun. Z.K, "Research on Gauss plume model,"Environment and Sustainable Development, vol.5, 2013.

[9] Zhuo. J.W,Li. B.W and Wei. Y.S, "The application of Matlab in Modeling,"Beijing: Beijing University of Aeronautics and Astronautics Press, 2014

[10] Yang. D, Zhao. H.B and Long. Z, "The application of Matlab in Image processing,”Beijing: Tsinghua University Press,2013. 